\title{
DOCUMENTA
}

\section{ANUARI MÈDIC DE BARCELONA DE L'ANY 1797}

\author{
SABATÉ I CASELLAS, Ferran \\ Unitat d'Història de la Medicina. Universitat de Barcelona (UB) \\ Barcelona (Barcelonès). sabate@ub.edu
}

Rebut: 11d'octubre de 2019

Acceptat: 23 d'octubre de 2019

PARAULES CLAU:

- Anuari

- Metges

- Barcelona

- Any 1797

- Acadèmia Mèdico-Pràctica

PALABRAS CLAVE:

- Anuario

- Médicos

- Barcelona

- Año 1797

- Academia Médico-Práctica

\section{KEYWORDS:}

- Yearbook

- Doctors

- Barcelona

- Year 1797

- Medical-Practice Academia
RESUM: Transcrivim el que considerem com un primer anuari de metges actius a la ciutat de Barcelona a l'any 1797. Això ens permet conèixer els seus noms, domicilis, categoria professional i càrrecs professionals ostentats així com l'organització i funcions de l'Acadèmia Mèdico-Pràctica" de Barcelona.

RESUMEN: Transcribimos el que consideramos un primer anuario de médicos activos en la ciudad de Barcelona en el año 1797. Esto nos permite conocer sus nombres, domicilio, categoría profesional y cargos profesionales ostentados. También conocer la organización y funciones de la Academia MédicoPráctica de Barcelona.

ABSTRACT. MEDICAL DOCTORS YEARBOOK OF BARCELONA OF THE YEAR 1797: We transcribe what we consider a first yearbook of active medical doctors in the city of Barcelona of the year 1797. It allows us to know their names, address, category professional and professional positions held. It allows too to know the organization and functions of the Academy Medical-Practice of Barcelona at that time.

CITACIÓ DE L'ARTICLE: SABATÉ i CASELLAS, Ferran. "Anuari Mèdic de Barcelona de l'any 1797 ". A: Gimbernat [Barcelona], 2020; 72: 131-140. http://doi.org/10.1344/gimbernat2020.72.8 


\section{INTRODUCCIÓ}

Entre la col·lecció de fullets de la donació d'Isidre Bonsoms a la Biblioteca de Catalunya, n'hem trobat un d'interès històrico-mèdic, el número 3.251. És una "Lista de los Medicos de la Ciudad de Barcelona, con expresión de su antigüedad, habitaciones y empleos".

Es tracta d'un petit llibret, de $200 \times 125 \mathrm{~mm}$, de 13 pàgines, imprès a Barcelona per Francisco Suria y Burgada a l'any 1798, per compte i ordre de la Reial Acadèmia Mèdico-Pràctica de Barcelona.

Això obeïa a una Reial Cèdula de S.M. del dia 7 de juny de l'any 1797, que manava publicar anualment, per part de la dita Acadèmia, el llistat complet dels seus membres i altres metges legalment autoritzats per a l'exercici de la professió a la ciutat de Barcelona. Aquests metges estaven obligats a prestar assistència sanitària gratuïta als pobres de solemnitat de Barcelona. Així mateix, per una Reial Ordre del 9 de febrer del mateix any, I'Acadèmia i els seus membres eren obligats a assistir, en cas d'epidèmia, a tot el Principat de Catalunya.

Ens trobem davant d'un primer precedent dels actuals directoris o guies mèdiques, que havia de tindre una edició o actualització anual. No hem trobat, ni a la Reial Acadèmia de Medicina de Catalunya ni a la Biblioteca de Catalunya, cap altre exemplar d'anys posteriors, el què ens fa pensar que no hi hagué continuitat, possiblement pel trasbals de la Guerra del Francès.

La finalitat d'aquesta "Lista" era informar al públic i als gremis i col·legis professionals i a les germandats de la ciutat de Barcelona, dels metges legalment autoritzats per a l'exercici de la medicina, prescriure medicaments d'ús intern, o signar certificats mèdics, tant en la pràctica pública com privada.

Encara que la majoria dels metges citats en aquesta "Lista" ja són coneguts i estan recollits en el Diccionari Biogràfic de Metges Catalans de J.M. Calbet Camarasa i J. Corbella Corbella, creiem d'utilitat la transcripció d'aquest llibret per les dades oficials que conté respecte a la composició i funcionament de l'Acadèmia Mèdico-Pràctica i la seva relació amb el conjunt de metges de Barcelona. Observem que no es fa cap esment als cirurgians ni als apotecaris. 


\section{“LISTA DE LOS MEDICOS DE LA CIUDAD DE BARCELONA, con expresión de su antigüedad, habitaciones y empleos.}

Arreglada conforme á lo mandado por S.M. en la Real Cedula de Adiciones á los Estatutos de la Real Académia de Medicina Practica de la expresada Ciudad con fecha de 7 Junio 1797.

Sirve para este año de 1798.

Barcelona: por Francisco Suria y Burgada. (Impresor)

\section{(I) ADVERTENCIA.}

La Facultad de Medicina de Barcelona insiguiendo la Real Cedula de S.M. de 7 de Junio de 1797, se compone actualmente de tres clases de Individuos; esto es, de Socios Residentes de la Real Académia de Medicina Practica, de Medicos Asociados á dicha Académia, y de Medicos no asociados á ella. Los Socios Residentes (según consta en la citada real Cedula) están limitados á veinte, y son los únicos que componen la Académia. Deben ser todos Doctores en Medicina, domiciliados en dicha ciudad de Barcelona ó Barceloneta, y de continua residencia á todas las Juntas Académicas. A estos solamente pertenecen y pertenecerán siempre privativamente la propiedad y uso de las salas donde se celebran las Juntas sobredichas, los bienes, honores, gracias, preeminencias y prerrogativas habidas y por haber en nombre de la citada Real Académia Medico-Practica de Barcelona.

Los Medicos Asociados son aquellos que se han asociado á la expresada Académia, insiguiendo lo dispuesto en la citada Real Cedula en los términos siguientes. Para unir del todo la Facultad Medica, en adelante la Real Académia Medico-Practica de Barcelona admitirá asociaciones de todos los Medicos ya establecidos en la misma Ciudad, ó que en lo sucesivo pretendan establecerse en ella para exercer la practica de la Medicina, y se llamarán Medicos Asociados á la Académia.

Los Medicos no Asociados son aquellos que sin ser Socios Residentes, ni Medicos Asociados pueden exercer la Medicina en Barcelona, 
porque estaban ya establecidos y domiciliados en la misma Ciudad antes de la fecha de la mencionada Real Cedula.

(III)

Sin embargo de que la citada Real Académia por los párrafos treinta y dos, treinta y tres, y treinta y quatro de sus Estatutos está obligada siempre que hubiese alguna epidemia, ú otro incidente contrario á la salud publica, á dar su dictamen, é indicar y practicar los medios con que pueda remediarse, y ademas de esto á dar su parecer sobre casos arduos que ocurran á los Socios; no obstante todos los Medicos Academicos Residentes ó Asociados estarán obligados á asistir de limosna á los pobres de solemnidad, cada uno en su respectivo barrio, Ilamando á consulta en los casos graves á los Medicos que parezca bien, y sean del agrado de los pobres, quienes concurrirán puntualmente, aunque vivan distantes, y sin honorario, teniendo ademas obligación la citada Académia de asistir por medio de sus Individuos con el debido zelo y prontitud á todas las epidemias que se verifiquen en dicha Ciudad de Barcelona y Principado de Cataluña, con arreglo á lo resuelto por N. R. P. en Real Orden de nueve de Febrero de este año.

(IX)

Para que el Publico tenga noticia de los sugetos que en Barcelona estan autorizados por las leyes del Reyno, y Cedula de Asociacion para exercer la Medicina Practica sin incurrir en pena alguna, á imitacion del Real Colegio de Medicina de esta nuestra Corte, se imprimirá anualmente una lista que contenga el nombre y apellido de cada uno, numero de casa y calle en que habita. Esta lista se arreglará empezando por los Socios Residentes según su antigüedad academica, seguirá después otra serie distinta con el titulo de Medicos Asociados á la Académia, segun el orden de antigüedad de grado.

Esta lista, que se repetirá todos los años á principios de Enero, se repartirá entre los Profesores de Medicina, Cirugía y Farmacia, y entre los Priores y Prohombres de los Colegios y Gremios de dicha Ciudad de Barcelona para que enterados de su contenido puedan valorar las Certificaciones de Medicos, que con tanta frequencia circulan entre ellos, y las Hermandades. A los que se asocien entre año se les despa- 
chará por el Secretario una certificación con que puedan hacerlo constar hasta que se imprima y reparta la lista del año venidero.

(XIII)

Ninguna persona, de qualquiera clase ó condición que fuere, no siendo Socio Residente, ó Medico Asociado, ó domiciliado en dicha Ciudad de Barcelona y sus Arrabales antes de la fecha de esta nuestra Carta, podrá en manera alguna exercer la Practica de la Medicina en la expresada Ciudad de Barcelona y sus Arrabales, ni prescribir publica ni privadamente medicinas determinadas al uso interno para la curación de las enfermedades, de la preñez, el puerperio, de la infancia, de las erisipelas, escorbuto, viruelas, sarampiones, hidropesías, garrotillos, fiebres intermitentes y remitentes, y todas las demás enfermedades, cuyo tratamiento es propio y peculiar de los Medicos, pena de cincuenta libras catalanas de multa por cada vez que contraviniere.

Los trozos de la Real Cedula de 7 Junio, que encierra la advertencia antecedente, están trasladados á la letra de lo que en la misma consta en las paginas 6 y 8 y en los párrafos III, IX y XIII. Barcelona 18 de Diciembre de 1797.

Dr. D. Francisco Sanponts, Socio Secretario.

SOCIOS RESIDENTES, que componen la Real Academia de Medicina Practica, según el orden de su antigüedad académica.

D. Ignacio Montanér, Medico honorario de Camara de S. M., VicePresidente de la Académia, Inspector de Drogas Medicinales. C. den Gignás, num. 7.

D. Luis Prats, Medico honorario de Familia de S. M., y Medico de Sanidad, C. dels Banys vells, num. 1.

D. Buenaventura Casals, Medico honorario de Familia de S. M., Tesorero de la Académia, é Inspector de Drogas Medicinales. Carreró de la Baixada de Sant Miquel, num. 2.

D. Francisco Salvá, Medico honorario de Familia de S. M., Secretario primero de la Académia, y Medico de la Real Casa de Hospicio y Hospital de Misericordia. C. den Petritxol, num. 21, ausente. 
D. Francisco Sanponts, Medico honorario de Familia de S. M., Secretario segundo de la Académia, y encargado interinamente de la primera Secretaria. C. de la Boqueria, num. 6.

D. Joseph Steva, Medico honorario de Familia de S. M., Examinador de la Asociacion, y del Real Protomedicato. C. Nou, num. 7.

D. Vicente Grassét, Medico honorario de Familia de S. M., Censor de la Académia, Examinador del Real Protomedicato, y Medico de Sanidad. Plassa de Palacio, num. 24.

D. Lorenzo Grassét, Medico honorario de Familia de S. M., Inspector de Epidemias de Cataluña delegado por la Académia, y Medico de Sanidad. En la Barceloneta, C. de Sant Andreu.

D. Narciso Roses, Medico honorario de Familia de S. M., y Medico segundo del Hospital General. C. de la Palla, num. 7.

D. Joseph Coll, Medico honorario de Familia de S. M., Secretario de la Académia para la correspondencia extranjera, y Examinador del Real Protomedicato. C. de Baséa, num. 19.

D. Vicente Mitjavila, Medico honorario de Familia de S. M., Socio Procurador de la Académia, é Inspector de Epidemias de Cataluña delegado por la misma. Plassa de Sant Just, num. 26.

D. Thomas Ventosa, Medico honorario de Familia de S. M., Medico de Numero de los Reales Exercitos, y Medico de la Real Carcel y Casa Galera. C. de la Palma de Santa Catharina, num. 20.

\section{CONTINUAN LOS SOCIOS RESIDENTES.}

15 D. Rafael Steva. C. dels Escudellers blanchs, num. 27.

14 D. Joseph Solá, Medico de residencia del Hospital General. En la misma casa.

17 D. Joseph Antonio Rigáls. C. den Gignás. Num. 9.

22 D. Pedro Tenas. Riera de Sant Joan, frente Santa Martha.

3 D. Salvador Ventosa. C. de la Palma de Santa Catharina, num. 20.

6 D. Francisco Pons, Examinador de la Asociacion, C. de la Enseñansa, num 1.

1 D. Gaspar Balaguer, Teniente de Proto-Medico de Cataluña. C. den Petritxol, num. 18.

23 D. Francisco Carbonell. C. de Sant Pere mes baix, num. 19. 


\section{MEDICOS ASOCIADOS A LA REAL ACADEMIA DE MEDICINA PRACTICA.}

2 D. Martín Valls. C. de Sant Pau, num. 51.

4 D. Lorenzo Font. Cerca la Plasseta del Regomí, num. 22.

5 D. Joseph Prat y Gual. C. dels Gegants, num. 11.

7 D. Antonio Millét, Medico de Numero de los Reales Exercitos. C. Nou, ausente.

8 D. Juan Janér. C. dels Banys vells, num. 17.

9 D. Francisco Colóm, Medico del Hospital General. C. de Sant Domingo, num. 4.

10 D. Raymundo Taulér. C. Mitjá de Sant Pere, num. 2.

11 D. Christoval Marimon, Medico de Numero de los Reales Exercitos, y Examinador de la Asociacion. Carreró de la Baixada de Sant Miquel.

12 D. Joseph Revert. C. Condal, num. 3.

13 D. Manuel Durán. Frente de Santa Catharina, num. 12.

16 D. Ramon Guasch. Plasseta de Marcús, num. 33.

18 D. Joseph Riera y Rafart, Medico de residencia del Hospital General. En la misma casa.

19 D. Juan Vahí, Medico de Numero de los Reales Exercitos. Plassa del Rey, num. 5.

20 D. Juan Brignét. En la Rambla, num. 1.

21 D. Narciso Planas, Examinador de la Asociacion. C. den Jaume Giralt, num. 15.

24 D. Dalvador Mas. C. den Robador, num. 60.

25 D. Juan Arenas. Plassa del Corréu, num. 7.

26 D. Antonio Molins. C. de la Boqueria, num. 6.

27 D. Domingo Prat. C. dels Gegants, num. 11.

28 D. Francisco Vila. C. dels Mercaders, num. 27.

29 D. Juan Doladér. C. de la Oliva de la Trinitát, num. 11.

30 D. Carlos Ronquillo. C. del Conde del Asalto, casa sin numero.

31 D. Abdon Saball, Medico de Numero de los Reales Exercitos. En la Barceloneta, C. de San Anton.

32 D. Joseph Carreras y Forns. C. del Carme, num. 13.

33 D. Alberto Riera. C. den Tarascó, num. 39.

34 D. Luis Costa. C. del Conde del Asalto, casa sin numero. 


\section{NOTA}

Aunque no estén continuados en la antecedente lista, por hallarse establecidos antes de la publicación de la Real Cedula en esta Ciudad, pueden también exercer en ella la Medicina los Profesores siguientes:

D. Antonio Marcelí. C. de Sant Honorat, num. 3.

D. Jayme Menós, Primer Medico de los Reales Exercitos. C. del Governador, num. 4.

D. Benito Pujol, Primer Medico del Hospital General, y Catedratico del Real Colegio de Cirugia. Plassa de la Trinitát, num. 12.

D. Juan Buscarons. En la Barceloneta, C. den Gamót.

D. Ignacio Ametllér, Medico de Numero de los Reales Exercitos. En la Boria, num. 1.

D. Miguel Carreras. C. de Jerusalém, num. 90.

D. Manuel Codorniu. Plassa de la Cucurulla, num. 31.

D. Salvador Pla. C. den Petritxol, num. 17.

D. Francisco Junoi, Catedratico del Real Colegio de Cirugia. C. den Petritxol, num. 13.

D. Francisco Poch. C. den Xuclá, num. 1."

(BIBLIOTECA DE CATALUNYA. "Lista de los Medicos de la Ciudad de Barcelona, con expresión de su antigüedad, habitaciones y empleos". Fons Isidre Bonsoms. Col·lecció de fullets, núm, 3.251)

\section{COMENTARIS}

Dels noms aquí mencionats, podem extreure que alguns d'ells ocuparen càrrecs destacats en l'administració sanitària d'aquell moment: Bonaventura Casals i Ignasi Montaner. Altres eren membres o examinadors del "Real Protomedicato": Joseph Steva i Vicente Grasset. Alguns eren "Inspector de Epidemias": Vicente Mitjavila i Fisonell, editor del "Semestre Medico Clínico" o Lorenzo Grasset. I encara, d'altres destacaren en l'àmbit de la recerca mèdica, elèctrica 0 meteorològica com Francesc Salvà i Campillo. També trobem que l'Acadèmia tenia un secretari per a la correspondència estrangera, en Joseph Coll; això ens informa que estaven al corrent dels avenços del coneixement que s'anaven produint arreu del món. 
Alguns d'aquests metges foren pioners del periodisme mèdic o tingueren un cert relleu cientific a nivell hispànic i internacional, i deixaren una obra escrita d'un cert mèrit científic, que cal tindre en consideració.

Atenent al seu origen, la majoria dels metges eren catalans. En trobem un de castellà, com: Juan Arenas, i un probable occità: Joan Brignét.

Observem que el secretari de l'entitat, Francisco Sanponts, mantingué la grafia original en català de les adreces mencionades dels metges llistats.

\section{BIBLIOGRAFIA}

BIBLIOTECA DE CATALUNYA. Fons Enric Bonsoms. Col-lecció de fullets, núm. 3.251.

CALBET I CAMARASA, Josep M.; CORBELLA I CORBELLA, Jacint. Diccionari Biogràfic de Metges

Catalans. 1a ed. Barcelona: Fundació Salvador Vives Casajuana-Seminari Pere Mata UB, 1981-1983. 3v. $772 \mathrm{p}$.

CORBELLA I CORBELLA, Jacint. "La Academia de Medicina de Barcelona". A: Historia y Vida [Barcelona], 1988; 21 (extra 49): 88-96.

CORBELLA I CORBELLA, Jacint; CALBET I CAMARASA, Josep M. "La funció de l'Acadèmia de Medicina en la Renaixença científica de Catalunya". A: Actes del Primer Congrés d'Història Moderna de Catalunya. Vol. II. Barcelona: Publicacions i Edicions de la Universitat de Barcelona, 1984, p. 597-602.

CORBELLA I COBELLA, Jacint. Memòries manuscrites de la Reial Acadèmia de Medicina de Catalunya. 1a ed. Barcelona: PPU, 1993. (Publicacions del Seminari Pere Mata; 52). 120 p.

FABRÉ, Jaume; HUERTAS, Josep M. Carrers de Barcelona: com han evolucionat els seus noms. Barcelona: Edhasa, 1982. 247 p.

IGLESIES, Josep. La contribució catalana al telègraf elèctric: Francesc Salvà i Campillo (1751-1828). 1a. ed. Barcelona: Rafael Dalmau Editor, 1965. 60 p. (Episodis de la història; 67).

LÓPEZ GÓMEZ, José. M. "Contribución al conocimiento de los inicios de la vacunación antivariólica en Cataluña". A: Gimbernat [Barcelona], 1989; 12: 167-177.

RIERA I TUĖBOLS, Santiago. "Salvà, precursor de Monturiol?”. A: Gimbernat [Barcelona], 1985; 5: 321-330.

RIERA I TUĖBOLS, Santiago. Ciència i tècnica a la Il/lustració: Francesc Salvà i Campillo (1751-1828). 1a. ed. Barcelona: La Magrana, 1985. 265 p. 


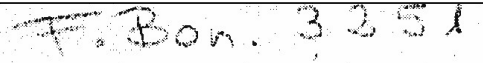

\section{I S T A \\ $D$ D}

DE LA CIUDAD

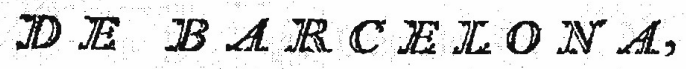

CON EXPRESION DE SU ANTIGUEDAD,

HABITACJONES Y EMPLEOS.

Arreglada conforme á lo mandado por S. M. en la Real Cedula de Adiciones á los Estatutos de la Real Académia de Medicina Practica de la expresada Ciudad con fecha de 7 . Junio 1797.

SIRVE PARA ESTE AIIO DE IT98.

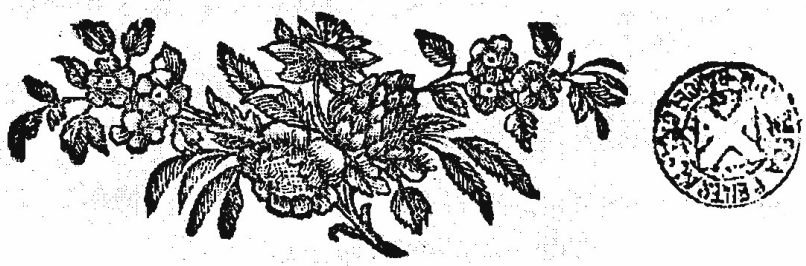

$B A R C E L O N A$ :

POR FRANCISCO SURIA Y BURGADA

Figura 1. Primera pàgina de la "Lista de los Medicos de la Ciudad de Barcelona, con expresión de su antigüedad, habitaciones y empleos".

(Font: Biblioteca de Catalunya. Fons Bonsoms. Col-lecció de fullets, núm. 3.251). 